\title{
EDITORIAL
}

\section{La Revista Boliviana de Cirugía Plástica}

\author{
Javier PACHECO-CARVAJAL \\ Cirujano Plástico. Editor de la Revista Boliviana de Cirugía Plástica \\ www.cirplasticabolivia.com
}

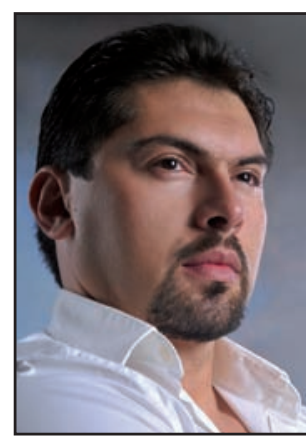

Pacheco Carvajal, J.
En el año 1992, en la ciudad de Sucre (Bolivia), se lanzó la Revista Boliviana de Cirugía Plástica (RBCP) como órgano oficial de difusión científica de la Sociedad Boliviana de Cirugía Plástica, Estética y Reconstructiva (SBCPER). La Dirección estaba a cargo del Dr. Guido Andrade Murillo, y se publicaron 3 números en los siguientes años en los que encontramos trabajos de investigación de colegas del país así como también de profesores extranjeros como los Dres. Alberto Rancatti y Fortunato Benaim.

Los recursos para dichas publicaciones provenían de los aportes de los miembros de la SBCPER. En 1994 se abandonó el proyecto; suponemos que las dificultades de la época para el envio de trabajos y el aspecto económico finalmente pesaron más.

En el año 2015, Bolivia, concretamente la ciudad de Santa Cruz de la Sierra, fue la anfitriona del Congreso Bolivariano de Cirugía Plástica, el evento regional de la FILACP más importante de nuestra especialidad, donde recibimos a los profesionales más destacados de nuestra área. La organización de este evento nos estimuló a concretar un sueño, que era el poder relanzar nuestra revista científica. Para que esto fuera posible, y conociendo las dificultades que tuvieron quienes nos precedieron, estructuramos un proyecto que en su primera etapa comprendió la firma de convenios de ayuda económica con casas comerciales y laboratorios para lograr la sostenibilidad económica de la revista en el tiempo.

En una segunda etapa invitamos y comprometimos a diferentes miembros de la SPCPER para ser parte del Comité de Redacción y de un Consejo Consultor Nacional. A fin de que estas instancias estén comunicadas y puedan trabajar de una manera ágil, habilitamos una secretaría permanente que trabaja en línea todo el año; por último, también contratamos los servicios de un diseñador gráfico.

Actualmente, la RBCP lleva 5 números publicados. En cada uno de sus ejemplares encontramos publicaciones de reconocidos profesores internacionales que con palabras de aliento nos envían permanentemente sus aportes, y publicaciones nacionales donde se pone en evidencia el gran trabajo que realizan los cirujanos plásticos bolivianos tanto en instituciones públicas como privadas, y que no siempre son reconocidos porque existe poca difusión del mismo.

La RBCP se convierte en el principal portal de la SBCPER, y principalmente nos sentimos orgullosos de este proyecto porque estamos motivando a sus miembros a la actividad científica, sabedores de que esto servirá para mejorar el nivel académico de nuestra especialidad. Nuestra RBCP es el paso que nos anima, que nos quita el temor a publicar y que nos permite ver que también podemos hacerlo en otras revistas reconocidas de nuestra especialidad.

Con gran orgullo recibimos recientemente la noticia de la aceptación del primer trabajo boliviano de esta nueva etapa para su publicación en la revista madre de nuestra especialidad en habla hispana, Cirugía Plástica Ibero-Latinoamericana.

Resalta la juventud de la gente que trabaja en nuestro Comité Editorial, que día a día se muestra más entusiasta y comprometida con el proyecto; claro ejemplo de esto es la redacción de nuestra visión y misión que fue encomendada a dicho Comité.

Visión: "Ser el medio de comunicación escrito y virtual más relevante de la Región Bolivariana, que recogerá experiencias, conocimientos e innovación en tratamientos quirúrgicos de reconocidos médicos nacionales e internacionales destinados a 
fortalecer, enriquecer aún más la Cirugía Plástica, y a su vez influir positivamente en la comunidad, siendo una herramienta consultiva para las actuales y futuras generaciones de cirujanos plásticos"

Misión: "Ser el Instrumento informativo y consultivo de la Cirugía Plástica en Bolivia y en la Región Bolivariana".

La RBCP y la SBCPER actualmente vienen trabajando en la organización de su Primer Curso de Redacción Científica que será dictado por la Dra. María del Mar Vaquero, Directora de Cirugía Plástica Ibero-Latinoamericana, el próximo mes de septiembre en la ciudad de Santa Cruz de la Sierra, evento al que invitamos a la Universidad Autónoma Gabriel René Moreno de Santa Cruz, al Colegio Médico de Bolivia con todas sus especialidades y a la Unidad de Postgrado de Salud de la Universidad Autónoma Gabriel René Moreno, quienes participan y a la vez brindan el aval institucional a nuestro evento. De esta manera queremos aportar y sembrar la motivación a la publicacion científica en toda la comunidad médica del país.
Nuestro Comité Editorial trabajará para que en un futuro mediato podamos indexar nuestra revista; sabemos que esto demandará mucho esfuerzo, pero tenemos esperanza en que sea reconocida más adelante como un instrumento de referencia científica. La motivación y la juventud de este comité nos hace creer que esto será posible; sin embargo, sabemos que estamos iniciando un largo camino donde lo primero que debemos hacer es brindarles a los miembros de la SBCPER las herramientas necesarias y el estímulo suficiente para empezar a publicar.

La secretaría de la RBCP se encuentra disponible de manera permanente para recibir trabajos y aclarar dudas a quienes quieran publicar en ella a través de la dirección de correo electrónico:

revistabcp2016@gmail.com

Todos los números publicados se encuentran disponibles en la página de la SBCPER:

www.cirplasticabolivia.com 